\title{
Association between Grain Size and Shape and Quality Traits, and Path Analysis of Thousand Grain Weight in Iranian Bread Wheat Landraces from Different Geographic Regions
}

\author{
Moslem ABDIPOUR ${ }^{1 *}$, Mohsen EBRAHIMI ${ }^{2}$, Ali IZADI-DARBANDI ${ }^{2}$, Anna Maria \\ MASTRANGELO ${ }^{3}$, Goodarz NAJAFIAN ${ }^{4}$, Yousef ARSHAD ${ }^{4}$, Gita MIRNIYAM ${ }^{2}$ \\ ${ }^{1}$ YoungResearchers and Elite Club, Gachsaran Branch, Islamic Azad University, Gachsaran, Iran; abdipur.m@ut.ac.ir ("correspondingauthor) \\ ${ }^{2}$ University of Tehran, College of Aburaihan, Department of Agronomy and Plant BreedingSciences, Tehran-Pakdasht, \\ Iran;mebrahimi@ut.ac.ir;aizady@ut.ac.ir;gmirniyam@ymail.com \\ ${ }^{3}$ Consiglioperlaricercain agricoltura l'analisidell'economia agraria, CentrodiRicercaperla Cerealicoltura(CREA-CER), Foggia, Italy; annamaria.mastrangelo@crea.gov.it \\ ${ }^{4}$ SeedandPlantImprovement ResearchInstitute,Karaj,Iran;goodarzn@yahoo.co.uk;yousefarshad@yahoo.com
}

\begin{abstract}
Grain characteristics, particularly grain weight, grain morphology, and grain protein content (GPC), are important components of grain yield and quality in wheat. A set of 98 bread wheat landraces from different geographic regions of Iran were used across 2013-2014 and 2014-2015 to determine the phenotypic diversity and relations between thousand grain weight (TGW), grain morphology and grain quality. A high-throughput method was used to capture grain size and shape. The genotypes were significantly different $(\mathrm{P}<0.001)$ for all traits which reflects the high levels of diversity. A moderate to high broad sense heritability was found for all traits and ranged between 0.68 and 0.95 for grain yield and factor from density (FFD), respectively. Significant positive correlations were observed between TGW and grain size (or shape) exception of aspect ratio (AR) and roundness. However, grain quality traits, especially GPC had significant negative correlation with TGW. Based on stepwise regression analysis by taking TGW as dependent variable, grain volume, FFD, width, perimeter and Hardness Index (HI) were recognized as the most important traits and explained more than $99.3 \%$ of total variation of TGW. The path analysis revealed that FFD has maximum direct effect on TGW followed by volume, whereas perimeter and width had relatively less direct effect on TGW. According to cluster analysis, landraces separated into 5 clusters, and cluster III and IV had the maximum and minimum average for the most traits, respectively. Our study provides new knowledge on the relations between TGW, grain morphology and grain quality in bread wheat, which may aid the improvement of wheat grain weight trait in further research.
\end{abstract}

Keywords: bread wheat, grain size and shape, grain quality, thousand grain weight, Triticum aestivum

\section{Introduction}

Wheat (Triticum aestivum $\mathrm{L}$.) as a strategic crop has a vital role in the developing countries economy and known as main food crop in abiotic stress prone areas which have low output productivity such as Iran (Abdipour et al., 2013). With increasing world population, it has been estimated that the global demand for wheat will increase by a further $60 \%$ by 2050 (Licker et al., 2010). It is a huge challenge to ensure global food security through sustainable wheat production for the projected population with the increasing adverse impact of climate change (Palm et al., 2010). So, it is necessary to continuously raise production mainly through higher yields. Accordingly, development of high yielding varieties with good end-use quality is a major focus in wheat breeding programs. In the past four decades, improvement of grain yield has come from increased grains per square meter or larger grain sizes, due to the utilization of $R h t$ genes in wheat breeding (Calderini and Reynolds, 2000). However, the breeding gains in wheat yield have substantially slowed in recent years due to the lack of 'breakthrough' germplasms and breeding methodologies (Jia et al.,2013). It has been proven that grain yield is a complex and quantitative trait that controlled by a number of genes with low heritability and it is significantly influenced by the environment, which make it difficult to be manipulated and improved in breeding programs (Koebner and Snape, 1999; Deng et al., 2011). Wheat grain yield can be divided into several direct components: spike number per unit area, grain number per spike, and TGW (Fuller, 2007; Wang et al., 2012). According to low heritability for most of the yield-related traits (Shi et al., 2009), and laborious, time-consuming, and costly to measure yieldrelated traits, assess all of them at the early stages of a breeding 
program is not benefit and practical. However, some components such as TGW are characterized by a higher heritability than grain yield itself (Bezant et al., 1997; Huang et al., 2006; Tsilo et al., 2010; Deng et al., 2011). TGW is positively correlated with agronomic yield (Baril 1992; Fuller, 2007; Maccaferri et al., 2011) and flour yield (Chasten et al., 1995; Breseghello and Sorrells, 2006; Williams et al., 2013). Moreover, the high heritability values (59\% to $96 \%$ ) in most of the cultivars studied so far have proved that this character is phenotypically the most-stable yield component (Giura and Saulescu, 1996; Huang et al., 2006; Sun et al., 2009; Tsilo et al., 2010; Patil et al., 2013). Therefore, together with the number of seeds per square meter, improved TGW is one of the main targets of wheat breeding activities. However, TGW is a complex trait, and is largely controlled by several grain traits, including grain size and shape (Zhang et al., 2014). Grain size is mainly characterized by grain weight and area, whereas shape means a relative proportion of the main growth axes of the grain (Breseghello and Sorrells, 2007; Gegas et al., 2010). While, grain shape is generally estimated by length, width, vertical perimeter, sphericity and horizontal axes proportion (Breseghello and Sorrells, 2007). Many studies have been shown that wheat grain size and shape is positively correlated with TGW and they have affected flour yield, end-use quality and market price (Evers et al., 1990; Breseghello and Sorrells, 2006; Tsilo et al., 2010; Cui et al., 2011; Blanco et al., 2012; Williams et al., 2013; Rasheed et al., 2014). Theoretical models predict that milling yield could be increased by optimizing grain size and shape with large and spherical grains being the optimum grain morphology (Evers et al., 1990). Although grain yield is one of the major determinants of a farmer's income, quality traits such as GPC is very important for bread-making quality. In more study, grain quality traits such as GPC in wheat have negatively correlated with grain yield and any genetic improvement in GPC has been restricted by the negative correlation between productivity and GPC (Kamra 1971; Bhatia 1975; Loffler and Busch, 1982; Blanco et al., 2012). Although grain yield and GPC are often negatively associated, some researchers reported wheat cultivars with high grain yield and high GPC in bread and durum wheat (Stuber et al., 1962; Johnson et al., 1973; Sears, 1998; De Ambrogio and Ranieri, 2002; Oury et al., 2003; De Ambrogio and Ranieri, 2002; Clarke et al., 2005). The primitive wheat species exhibit broad variation in grain size and shape, and quality in contrast to modern wheat varieties, meaning that the modern breeding germplasm has lost grain morphology and quality variation, probably due to selection for more uniform grain shape and a certain quality in the elite varieties (Gegas et al., 2010). In this context, landraces, wild forms and other related wild species can have crucial roles in breeding programs because of their wide variability in terms of phenological, morphological, abiotic, biotic and quality traits (Moragues et al., 2006 and 2007; Peleg et al., 2008). However, accurate characterization of grain size and shape remains a big challenge due to laborious, time consuming techniques (in particular in large sets of samples) and complex nature of wheat grain shape. (Houle et al., 2010; Patil et al., 2013). More recently, a high-throughput method was used to capture grain size and shape variations in multiple mapping populations, elite varieties, and in a broad collection of ancestral wheat species (Gegas et al., 2010; Williams et al., 2013;Okamoto et al., 2013; Williams and Sorrells, 2014; Rasheed et al., 2014). The majority of these studies have been performed for only some grain morphology traits without quality traits. Therefore, in spite of the importance of these traits, a severe lack of information on the some important grain morphology and quality traits and as well as the association between TGW and grain morphology, and quality traits in bread wheat is evident. So, the evaluation of grain shape and size and the association between TGW and grain morphology can be useful in this case.

For this purpose, a collection of 98 bread wheat landraces from different geographic regions of Iran along with two local bread cultivar as check evaluated for TGW, grain morphology and quality traits. The present study was initiated (i) to determine the level of heritability, phenotypic and genotypic diversity of TGW, grain morphology and quality traits, (ii) identify association between TGW and other traits and develop best model to identify selection indirect indices for TGW (iii) and, the screen the best genotypes group based on studied traits.

\section{Materials and Methods}

\section{Plant materials and field trials}

A set of 100 bread wheat genotypes included 98 Iranian bread wheat landraces plus two additional check varieties as the best locally adapted cultivars used as plant materials in this study. This collection of bread wheat landraces were selected from 27 provinces that were classified into five groups based on their geographic origins. These landraces were generally winter hardy with different heading dates and flowering times. The genotype panel was planted under the open-field conditions in during the two growing seasons (2013/2014 and 2014/2015) at the experimental farm of College of Aburaihan, University of Tehran, Tehran (Pakdasht), Iran (53 28' N, 50 581' E; $1180 \mathrm{~m}$ above sea level). The soil included clay (32\%), loam (39.2\%) and sand (29.2\%). The experiments followed a $10 \times 10$ square lattice design with three replications. Each cultivar was planted in two-row plots with a length of $2 \mathrm{~m}$ and $30 \mathrm{~cm}$ spacing rows (with 40 seeds per row). The grain yield $\mathrm{ha}^{-1}$ was calculated based on the plot area $\left(0.6 \mathrm{~m}^{2}\right)$.

\section{Phenotypic evaluation}

Whole plots were harvested on 31 May 2014 and 15 June 2015 and stored at $4{ }^{\circ} \mathrm{C}$ until analysis. A minimum of 500 grains sound, intact grains were selected for evaluation. Undamaged, non-shriveled grains which excluded the occasionally extremely large or extremely small grains seen in some threshed samples were included as representative of each line. In this study, grain yield, TGW, nine grain morphology traits including; grain length, width, thickness, roundness, area, FFD, volume, perimeter, AR, and five grain quality traits including; GPC, Zeleny sedimentation (ZS), water absorption (WA), hardness index (HI), falling number $(\mathrm{FN})$ were evaluated. The measurements of TGW, grain length, width, thickness, roundness, area, perimeter and AR were performed directly using the a digital grain analyzer assisted by an automatic digital image analysis suite that allowed highthroughput data collection from a large number of grains and lines. The quality traits was determined on whole-meal flour using nearinfrared reflectance spectroscopy. The FFD describes the differences in grain density and the deviation of a shape from a cylindrical form, and was calculated using the formula in Eq. (1): (Giura and Saulescu, 1996):

$$
F F D=\frac{\text { grain weight }}{(\text { grain width } \times \text { grain lenght })}
$$


230

The grain volume was approximated as $\mathrm{VOL}_{\mathrm{xyz}}$ using the formula for volume of an ellipsoid (Eric W. Weisstein, Ellipsoid, from MathWorld: http://mathworld.wolfram.com/Ellipsoid. html) based on $\mathrm{x}, \mathrm{y}$, and $\mathrm{z}$ axes corresponding to grain width, length, and thickness measures (respectively) from grain counter using the formula in Eq.(2):

$$
V O L_{x y z}=\left(\frac{4}{3}\right) \pi x y z
$$

\section{Statisticalanalysis}

The frequency distributions of the phenotypic data were tested for normal distributions (with Kolmogorov-Smirnov test) to estimate the complexity of the genetic control of the traits. Analysis of variance (ANOVA) was performed to test the significance of source of variation and the efficiency of the lattice design compared to a randomized complete block design, using the PROC LATTICE statement in the SAS Version 9.0 (SAS Institute, Inc., Cary, NC). Since the efficiency of the lattice design compared to a randomized complete block design for all traits is less than 105 percent, the ANOVA and other analysis were performed based on the randomized complete block design.

The values of variance obtained from the ANOVA were used to calculate the broad sense heritability $\left(h_{B}^{2}\right)$, using the formula in Eq. (3):

$$
h_{B}^{2}=\frac{\frac{\left(\delta^{2} e+r \delta^{2} g y+r y \delta^{2} g\right)-\delta^{2} e+r \delta^{2} g y}{y}}{\frac{\left(\delta^{2} e+r \delta^{2} g y+r y \delta^{2} g\right)-\delta^{2} e+r \delta^{2} g y}{r y}+\delta^{2} e}
$$

where $\delta^{2} e$ is the error variance, $\delta^{2} g y$ is the genotypic and year interaction variance, $\delta^{2} g$ is the genotypic variance, $r$ is the number of replication and $y$ is the number of year.

The genotypic covariance and variance among traits were calculated using the PROC GLM and multiple analysis of variance (MANOVA) in SAS. The genotypic correlation coefficients were calculated using the formula in Eq.(4):

$$
r_{g}=\frac{\delta_{g x y}}{\sqrt{\left(\delta_{g x}^{2}\right)\left(\delta_{g y}^{2}\right)}}
$$

where $\delta_{g x y}$ is the genotypic covariance between $\mathrm{x}$ and $\mathrm{y}$ traits, $\delta_{g x}^{2}$ and $\delta_{g y}^{2}$ are the genotypic variance for $\mathrm{x}$ and $\mathrm{y}$ traits, respectively.

In order to determine the best combination of variables that determinate grain weight in bread wheat landraces a stepwise regression analysis was employed by taking TGW as dependent variable and other traits as independent variables, using the formula in Eq.(5):

$$
y=a+b_{1} x_{1}+b_{2} x_{2}+b_{3} x_{3}+\ldots+b_{i} x_{i}
$$

where, $y$ is the dependent variable (TGW), the x's are independent variables (measured traits) affecting dependent one, $a$ is the intercept coefficient, and the $b$ 's are the related coefficients of independent variables in predicting the dependent variable.

To estimate the contribution of individual characters to grain yield, a path coefficient analysis using TGW as dependent variable and variables that remained in model as independent variables was computed.

In order to classify the genotypes, a hierarchical cluster analysis was carried out based on ward's method (Ward, 1963) and the similarity matrix, and the resulting dendrogram was drawn by IBM SPSS Statistics 22.0.0 software (http://www.brothersoft.com/ibm-spss-statistics-469577.html). MANOVA method was used to determine the correct cut-off point of clusters. We used four statistics in MANOVA, including: Wilks' Lambda, Pillai's Trace, Hotelling-Lawley Trace and Roy's Greatest Root statistics by SAS Version 9.0 (SAS Institute, Inc., Cary, NC).

\section{Results}

\section{Variation and heritability}

The raw data of combined experiments across two years were checked for normal distributions, and the variation for grain weight, grain morphology and grain quality measures were tested by two-way ANOVA (Table 1).

Four sources of variation were considered: year, block in year, genotype, and genotype $\times$ year. There were significant differences between two years for most of the traits with the exception of

Table 1. Combined analysis of variance for bread wheat landraces over two years (2013-2015)

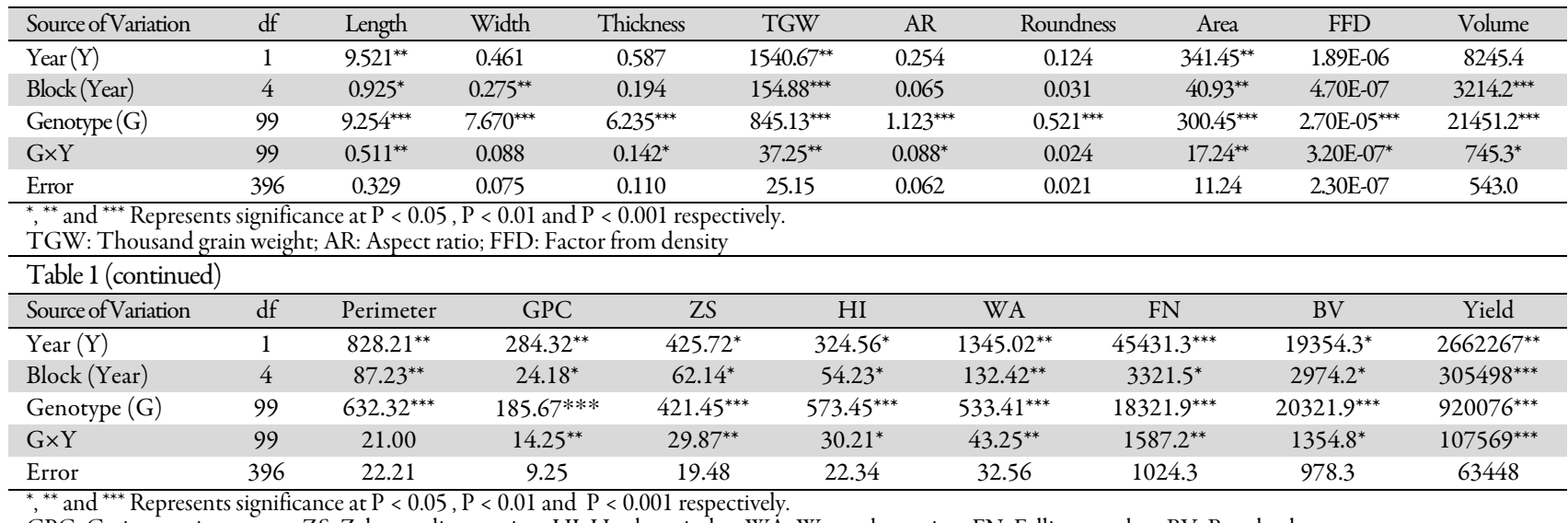

GPC: Grain protein content; ZS: Zeleny sedimentation; HI: Hardness index; WA: Water absorption; FN: Falling number; BV: Bread volume 
Table 2. Phenotypic variation for grain weight, grain size (and shape) and grain quality traits over two years (2013-2015)

\begin{tabular}{|c|c|c|c|c|c|c|}
\hline Variables & Minimum & Maximum & Mean \pm SD & $\mathrm{CV}(\%)$ & $\delta^{2} G$ & $h^{2}(\%)$ \\
\hline Length & 4.85 & 9.64 & $7.26 \pm 0.57$ & 7.90 & 1.46 & 81.58 \\
\hline Width & 2.66 & 4.52 & $3.35 \pm 0.27$ & 8.17 & 1.26 & 94.40 \\
\hline Thickness & 2.34 & 4.07 & $3.19 \pm 0.33$ & 10.41 & 1.02 & 90.23 \\
\hline TGW & 26.2 & 68.7 & $50.07 \pm 5.01$ & 10.02 & 134.65 & 84.26 \\
\hline AR & 1 & 3.22 & $2.11 \pm 0.25$ & 11.82 & 0.17 & 73.56 \\
\hline Roundness & 0.43 & 0.99 & $0.68 \pm 0.14$ & 21.27 & 0.08 & 79.78 \\
\hline Area & 8.1 & 26.5 & $17.48 \pm 3.35$ & 19.18 & 47.20 & 80.77 \\
\hline FFD & $1.29 \mathrm{E}-03$ & $2.89 \mathrm{E}-03$ & $2.06 \mathrm{E}-03 \pm 4.8 \mathrm{E}-04$ & 23.29 & $4.45 \mathrm{E}-06$ & 95.08 \\
\hline Volume & 159.07 & 458.02 & $326.53 \pm 23.30$ & 7.14 & 3450.98 & 86.40 \\
\hline Perimeter & 13.71 & 28.07 & $22.78 \pm 4.71$ & 20.69 & 101.89 & 82.10 \\
\hline GPC (\%) & 13.3 & 14.7 & $14.04 \pm 3.04$ & 21.66 & 28.57 & 75.54 \\
\hline ZS & 35 & 37 & $35.74 \pm 4.41$ & 12.35 & 65.26 & 77.01 \\
\hline $\mathrm{HI}$ & 46 & 55 & $51.12 \pm 4.73$ & 9.25 & 90.54 & 80.21 \\
\hline WA (\%) & 63.2 & 66 & $64.38 \pm 5.71$ & 8.86 & 81.69 & 70.50 \\
\hline FN & 330 & 663 & $513 \pm 32$ & 6.24 & 2789.12 & 73.14 \\
\hline BV & 435 & 554 & $501 \pm 31.27$ & 6.24 & 4139.14 & 76.37 \\
\hline Yield & 800 & 9188.89 & $4027.97 \pm 251.89$ & 6.25 & 135417.83 & 68.10 \\
\hline
\end{tabular}

SD: Standard deviation; CV: Coefficient of variation; $\delta^{2}$ G: Genotypic variance; $h^{2}$ : Broad sense heritability; TGW: Thousand grain weight; AR: Aspect ratio; FFD: Factor from density; GPC: Grain protein content; ZS: Zeleny sedimentation; HI: Hardness index; WA: Water absorption; FN: Falling number; BV: Bread volume

Table 3. Coefficients of genotypic correlation for grain weight, grain size (and shape) and grain quality traits over two years (2013-2015)

\begin{tabular}{|c|c|c|c|c|c|c|c|c|c|}
\hline Variable & Length & Width & Thickness & TGW & $\mathrm{AR}$ & Roundness & Area & FFD & Volume \\
\hline Width & 0.090 & 1 & & & & & & & \\
\hline Thickness & $0.290^{* *}$ & $0.456^{* *}$ & 1 & & & & & & \\
\hline TGW & $0.694^{* *}$ & $0.388^{* *}$ & $0.608^{* *}$ & 1 & & & & & \\
\hline AR & $0.646^{* *}$ & $-0.585^{* *}$ & -0.079 & 0.156 & 1 & & & & \\
\hline Roundness & 0.023 & 0.064 & $0.225^{*}$ & 0.055 & 0.149 & 1 & & & \\
\hline Area & $0.740^{* *}$ & $0.681^{* *}$ & $0.564^{* *}$ & $0.653^{* *}$ & 0.119 & 0.033 & 1 & & \\
\hline FFD & 0.157 & -0.177 & $0.270^{* *}$ & $0.647^{* *}$ & 0.125 & 0.044 & -0.044 & 1 & \\
\hline Volume & $0.665^{* *}$ & $0.705^{* *}$ & $0.787^{* *}$ & $0.753^{* *}$ & 0.018 & 0.142 & $0.919^{* *}$ & 0.063 & 1 \\
\hline Perimeter & $0.969^{* *}$ & $0.329^{* *}$ & $0.387^{* *}$ & $0.753^{* *}$ & $0.481^{* *}$ & 0.039 & $0.839^{* *}$ & 0.169 & $0.802^{* *}$ \\
\hline GPC (\%) & 0.124 & -0.028 & $-0.256^{* *}$ & $-0.210^{*}$ & 0.165 & $0.303^{* *}$ & -0.032 & $-0.420^{* *}$ & -0.072 \\
\hline ZS & -0.121 & -0.111 & -0.108 & -0.055 & -0.005 & 0.06 & $-0.240^{*}$ & 0.098 & -0.142 \\
\hline HI & -0.048 & 0.189 & -0.089 & -0.105 & -0.148 & 0.004 & 0.033 & $-0.231^{*}$ & 0.032 \\
\hline WA (\%) & 0.127 & 0.159 & $-0.205^{*}$ & -0.167 & -0.040 & $-0.223^{*}$ & 0.120 & -0.481 & 0.031 \\
\hline FN & 0.048 & $-0.255^{*}$ & -0.174 & 0.040 & $0.228^{*}$ & 0.086 & -0.080 & 0.196 & -0.180 \\
\hline BV & 0.064 & -0.172 & -0.193 & -0.019 & 0.115 & $-0.250^{*}$ & -0.112 & 0.030 & -0.141 \\
\hline Yield & $0.212^{*}$ & $0.296^{* *}$ & $0.352^{* *}$ & $0.448^{* *}$ & -0.150 & 0.012 & $0.267^{* *}$ & $0.234^{* *}$ & $0.375^{* *}$ \\
\hline $\begin{array}{l}{ }^{*} \text { and }{ }^{* *} \text { Rep } \\
\text { protein cont }\end{array}$ & eleny sedimer & 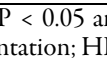 & $\begin{array}{l}0.01 \text { res } \\
\text { nness inde }\end{array}$ & $\begin{array}{l}\text { ively. TGW } \\
\text { VA: Water a }\end{array}$ & $\begin{array}{l}\text { ousand gra } \\
\text { tion; FN: }\end{array}$ & $\begin{array}{l}\text { t; AR: Asp } \\
\text { umber; } B V\end{array}$ & $\begin{array}{l}\text { tio; FFD: Fa } \\
\text { d volume }\end{array}$ & from den & SPC: Grai \\
\hline \multicolumn{10}{|c|}{ Continued Table 3.} \\
\hline Variable & Perimeter & & $(\%)$ & $\mathrm{ZS}$ & $\mathrm{HI}$ & WA (\%) & $\mathrm{FN}$ & BV & Yield \\
\hline GPC (\%) & 0.106 & & & & & & & & \\
\hline ZS & -0.143 & & & 1 & & & & & \\
\hline $\mathrm{HI}$ & -0.005 & & & $0.200^{*}$ & 1 & & & & \\
\hline WA (\%) & 0.153 & & & 0.176 & $0.477^{* *}$ & 1 & & & \\
\hline FN & -0.014 & & & -.020 & -0.013 & -0.198 & 1 & & \\
\hline BV & 0.019 & & & -0.028 & -0.185 & $0.252^{*}$ & -0.149 & 1 & \\
\hline Yield & $0.264^{* *}$ & & & -0.114 & -0.172 & $-0.231^{*}$ & -0.134 & 0.03 & 1 \\
\hline
\end{tabular}

${ }^{*}$ and ${ }^{* *}$ Represents significance at $\mathrm{P}<0.05$ and $\mathrm{P}<0.01$ respectively.

GPC: Grain protein content; ZS: Zeleny sedimentation; HI: Hardness index; WA: Water absorption; FN: Falling number; BV: Bread volume

grain width, thickness, AR, roundness, FFD and volume. However, due to the large number of traits and the large volume of data we used the average of two years for other analysis. Significant differences were observed for all traits with the exception of thickness, AR, roundness and FFD for block (year) effect. However, the genotypes showed very significant differences $(\mathrm{P}<0.001)$ for all traits. On the other hand, all traits with the exception of the grain width, roundness and perimeter showed significant differences for year $\times$ genotype effect. Relative to genotype main effects, the magnitude of year $\times$ genotype interaction effects was often small.
The phenotypic data for grain weight, grain morphology and grain quality descriptors were averaged from two cropping seasons in 2103-2014 and 2014-2015. For the traits evaluated, the means and ranges, the coefficient of variation, the genotypic variance and heritability estimates presented in Table 2. The high differences between the minimum and maximum of studied traits is a result of high difference between genotypes. This collection of diverse genotypes with such ideal levels for traits can be use as a good source for diversity and mapping studies.

A moderate to high broad sense heritability was found for all traits and ranged between 0.68 and 0.95 for grain yield and FFD, 
232

respectively. The moderate to high heritability values are an index of the weak environmental effect. The all grain size and shape traits with the exception of the AR and roundness had over 80 percent heritability. However, the heritability for quality traits ranged 0.70 and 0.80 for WA and HI, respectively.

\section{Genotypic correlation}

The coefficients of genotypic correlation were calculated for all traits as means from the two growing seasons (Table 3). Grain length and perimeter showed the maximum positive correlation (0.97), followed by $r=0.92$ between grain area and volume. By contrast, grain width and AR showed the maximum negative correlation $(-0.59)$, followed by $r=-0.42$ between FFD and GPC. Interestingly, the correlations between all grain shape direct measurements and grain weight were positive and very significant. For example, grain length and width were highly correlated with TGW with estimate of $r=0.69$ and $r=0.39$, respectively. Similarly, grain thickness was highly correlated with TGW (r $=0.61$ ). The other grain morphology traits with the exception of the AR and roundness had highly positive correlation with TGW. The among quality traits, just FN had very low positive association with TGW $(\mathrm{r}=0.04)$ and the other traits as negatively correlated with TGW, from -0.09 to -0.210 for HI and GPC, respectively.

\section{Stepwise regression analysis and path coefficient analysis}

A stepwise regression analysis was computed in order to eliminate no effective variables on grain weight in regression model and study only traits affecting significantly grain weight changes by taking TGW as dependent variable (Table 4). Based on this method, grain volume as the first entered variable in model was the most important character and had the strongest variation in TGW. This model could justify significantly more than 56 percent changes in performance. Four variables, including FFD, width, perimeter and $\mathrm{HI}$ respectively were entered to regression model after grain volume. In final step, these variables with grain volume had justified $99.33 \%$ of TGW variation (Table 5). Regression coefficients for the accepted variables are shown in Eq.(6). Therefore, based on the final step of stepwise regression analysis, the equation for prediction of TGW was computed as follows:

$y=-69.16+0.00012 x_{1}+23326 x_{2}+9.81 x_{3}+1.81 x_{4}-0.057 x_{5}$

Where, $\mathrm{y}$ is the TGW; $\mathrm{x} 1, \mathrm{x} 2, \mathrm{x} 3, \mathrm{x} 4$ and $\mathrm{x} 5$ are grain volume, FFD, width, perimeter and $H I$, respectively.

A path coefficient analysis was computed by taking TGW as dependent variable, in order to have a clear understanding of the effect of individual measurement on TKW, and grain volume, FFD, width, perimeter and $\mathrm{HI}$ as independent variables (Table 6). FFD exhibited maximum positive direct effect on grain weight followed by volume. Grain perimeter and width had moderate to low positive direct effects on grain weight, respectively. However, protein has a poor negative direct effect on grain weight.

\section{Cluster analysis}

In order to categorize genotypes that are similar into one group and others into different groups, a cluster analysis used. The most $F$ value for all statistics in MANOVA obtained when the cluster divided into five groups (Table 7). So, the cluster divided into five groups and genotypes separated into groups. Cluster I to $\mathrm{V}$ consisted of 35, 39, 2, 2 and 22 genotypes, respectively. Cluster II with $39 \%$, and cluster III and IV with $2 \%$ of total genotypes were recognized as the largest and the smallest clusters, respectively. The average and standard deviation of traits for each cluster from ground mean are shown in Table 8. A diagram of cluster analysis (dendrogram) is given in Fig. 1.

\section{Discussion}

Grain characteristics, particularly grain weight, grain size and shape, and grain protein, are important components of grain yield and quality in wheat due to their significant effect on grain yield, milling yield, end-use quality and market price. In recent years advances in phenotypic measurements have fallen behind progress in highthroughput geno-typing. In order to take full advantage of low-cost genotyping resources, plant breeders are aggressively pursuing more accurate and efficient phenotyping methods (De Souza, 2010; Houle et al., 2010; Montes et al., 2007). Manual measurement methods of grain morphology have limits to the number of data, the quality of measurements, and the variety of shape data that can be gleaned. By contrast, computational methods using digital image technology could enable us to automatically measure robust grain size and shape descriptors (Williams et

Table 4. Stepwise regression on the TGW as dependent variable over two years (2013-2015)

\begin{tabular}{lccc}
\hline Source of variation & df & Mean Square & F \\
\hline Model & 5 & 1172.62 & $2430.91^{* * *}$ \\
Error & 94 & 0.4823 & \\
Corrected total & 99 & & \\
\hline${ }^{* * *}$ Represents significance at $\mathrm{P}<0.001$ & &
\end{tabular}

Table 5. Relative contribution (partial and model $\mathrm{R}^{2}$ ) and $\mathrm{F}$ value in predicting TGW by stepwise regression over two years (2013-2015)

\begin{tabular}{lccc}
\hline Variable in Model & $\begin{array}{c}\text { Partial R- } \\
\text { Square }\end{array}$ & $\begin{array}{c}\text { Model R- } \\
\text { Square }\end{array}$ & $\mathrm{F}$ \\
\hline Volume & 0.5618 & 0.5618 & $125.64^{* * *}$ \\
FFD & 0.3481 & 0.9090 & $374.81^{* * *}$ \\
Width & 0.0816 & 0.9915 & $925.80^{* * *}$ \\
Perimeter & 0.0010 & 0.9925 & $12.02^{\text {*** }}$ \\
HI & 0.0009 & 0.9933 & $12.12^{\text {*** }}$ \\
\hline${ }^{* * *}$ Represents significance at $\mathrm{P}<0.001$ & &
\end{tabular}

FFD: Factor from density; HI: Hardness index

Table 6. Direct (diagonal and bold) and indirect effects of variables remained in stepwise regression model on TGW over two years (2013-2015)

\begin{tabular}{lccccc}
\hline Variable & Volume & FFD & Perimeter & Width & HI \\
\hline Volume & $\mathbf{0 . 3 9 2}$ & 0.037 & 0.239 & 0.083 & -0.001 \\
FFD & 0.024 & $\mathbf{0 . 5 9 2}$ & 0.05 & -0.021 & 0 \\
\hline Perimeter & 0.315 & 0.1 & $\mathbf{0 . 2 9 9}$ & 0.038 & 0 \\
Width & 0.276 & -0.105 & 0.098 & $\mathbf{0 . 1 1 7}$ & -0.001 \\
\hline HI & 0.012 & -0.137 & -.002 & 0.022 & $\mathbf{- 0 . 0 0 2}$ \\
Residual effect & 0.223 & & & & \\
\hline FFD Factor from density: HI. Hardness index
\end{tabular}

FFD: Factor from density; HI: Hardness index

Table 7. MANAOVA of bread wheat landraces for 5 clusters

\begin{tabular}{lcc}
\hline Statistic & Value & F Value \\
\hline Wilks' Lambda & 7.431 & $32.74^{* * *}$ \\
Pillai's Trace & 10.424 & $21.24^{* * *}$ \\
\hline Hotelling-LawleyTrace & 354.625 & $82.77^{* * *}$ \\
Roy's Greatest Root & 276.025 & $299.11^{* * *}$ \\
\hline
\end{tabular}

${ }^{* * *}$ Represents significance at $\mathrm{P}<0.001$ 
Table 8. Mean and standard deviation of grain weight, grain size (and shape) and grain quality traits over two years (2013-2015)

\begin{tabular}{lccccc}
\hline Variable & Cluster I & Cluster II & Cluster III & Cluster IV & Cluster V \\
\hline Length & $7.39 \pm 0.52$ & $7.59 \pm 0.45$ & $7.80 \pm 0.20$ & $5.29 \pm 0.32$ & $6.59 \pm 0.65$ \\
Width & $3.26 \pm 0.22$ & $3.57 \pm 0.20$ & $3.72 \pm 0.16$ & $3.14 \pm 0.05$ & $3.11 \pm 0.19$ \\
\hline Thickness & $3.16 \pm 0.14$ & $3.35 \pm 0.18$ & $3.70 \pm 0.27$ & $2.53 \pm 0.08$ & $2.95 \pm 0.17$ \\
TGW & $50.55 \pm 6.75$ & $55.59 \pm 4.80$ & $53.50 \pm 0.17$ & $30.87 \pm 0.43$ & $40.95 \pm 6.04$ \\
\hline AR & $2.21 \pm 0.31$ & $2.06 \pm 0.26$ & $2.12 \pm 0.04$ & $1.62 \pm 0.11$ & $2.07 \pm 0.35$ \\
Roundness & $0.69 \pm 0.12$ & $0.69 \pm 0.13$ & $0.81 \pm 0.09$ & $0.64 \pm 0.04$ & $0.64 \pm 0.10$ \\
\hline Area & $17.12 \pm 1.46$ & $19.46 \pm 1.29$ & $21.48 \pm 0.55$ & $11.15 \pm 0.65$ & $14.76 \pm 1.31$ \\
FFD & $2.11 \mathrm{E}-03 \pm 2.69 \mathrm{E}-04$ & $2.06 \mathrm{E}-03 \pm 2.02 \mathrm{E}-04$ & $1.85 \mathrm{E}-03 \pm 1.32 \mathrm{E}-04$ & $1.87 \mathrm{E}-03 \pm 1.14 \mathrm{E}-04$ & $2.00 \mathrm{E}-03 \pm 2.24 \mathrm{E}-04$ \\
\hline Volume & $317.56 \pm 15.73$ & $378.34 \pm 20.93$ & $448.19 \pm 1.63$ & $175.51 \pm 7.48$ & $251.61 \pm 17.52$ \\
Perimeter & $23.03 \pm 1.63$ & $24.49 \pm 1.41$ & $25.62 \pm 1.12$ & $15.15 \pm 1.24$ & $19.77 \pm 2.12$ \\
\hline GPC (\%) & $14.13 \pm 0.39$ & $14.02 \pm 0.44$ & $14.05 \pm 0.35$ & $14.15 \pm 0.55$ & $14.00 \pm 0.46$ \\
ZS & $35.83 \pm 0.56$ & $35.85 \pm 0.58$ & $36.00 \pm 0.00$ & $36.00 \pm 1.00$ & $35.91 \pm 0.60$ \\
\hline HI & $50.97 \pm 2.12$ & $50.62 \pm 2.34$ & $53.00 \pm 1.00$ & $52.50 \pm 2.50$ & $50.86 \pm 2.36$ \\
WA (\%) & $64.43 \pm 0.68$ & $64.44 \pm 0.63$ & $64.45 \pm 0.25$ & $64.65 \pm 1.05$ & $64.36 \pm 0.67$ \\
\hline FN & $500.14 \pm 26.21$ & $500.33 \pm 25.43$ & $452 \pm 17$ & $500 \pm 11$ & $506.68 \pm 23.91$ \\
BV & $500 \pm 26$ & $500 \pm 25$ & $452 \pm 17$ & $500 \pm 11$ & $506 \pm 24$ \\
\hline Yield & $3899.11 \pm 1389.74$ & $4563.06 \pm 1299.54$ & $4455.56 \pm 374.07$ & $3388.89 \pm 877.78$ & $3303.64 \pm 1374.39$ \\
Number of genotypes & 35 & 39 & 2 & 2 & 22 \\
\hline TGW: Thousnd
\end{tabular}

TGW: Thousand grain weight; AR: Aspect ratio; FFD: Factor from density; GPC: Grain protein content; ZS: Zeleny sedimentation; HI: Hardness index; WA: Water absorption; FN: Falling number; BV: Bread volume

al., 2013). Only few studies are available based on digital image analysis of grain size and shape in bread wheat (Williams et al., 2013; Gegas et al., 2010; Williams and Sorrells, 2014; Breseghello and Sorrells, 2007; Xiao et al., 2011; Rasheed et al., 2014; Zhang et al., 2015). Among these studies, Gegas et al., 2010; Williams et al. (2013), Williams and Sorrells (2014) and Rasheed et al. (2014), used shape variations as targeted traits influencing grain size and weight and results are comparable to our work. However, the most of them just used some grain morphology traits and didn't use any quality traits. The high significant differences $(\mathrm{P}<0.001)$ among genotypes for all traits indicating the presence of adequate variability among the bread wheat local landraces which can be used for the improvement of grain weight and quality in order to create high yielding varieties with good end-use quality. Though compare the measures for traits such as grain size and shape in different studies because of different approaches to converting raw images into quantitative data is not completely correct, differences between high and low level for the most traits in this study are more in compared with other studies such as Sun et al. (2009), Tsilo et al. (2010), Jia et al. (2013) and Zhang et al. (2015). Due to the high diversity, it seems can find suitable genotypes with high and low limit bounds for two or more traits as versus each other. For example, two genotype 97 and 42 with 9.64 and 7.58 length, and with 3.43 and 4.53 width can used as parents to create segregation populations for quantitative trait loci (QTL) studies. Despite the high variety and acceptable quality of Iranian bread wheat landraces, it seems these genotypes had lower quality compared with some bread populations in Blanco et al. (2012) and Kalous et al. (2015) studies.

Similar to the results of other researchers (Huang et al., 2006; Sun et al., 2009; Tsilo et al., 2010; Blanco et al., 2012 and Patil et al., 2013), the grain yield with the lowest heritability, more than other traits had influenced by environmental factors. By contrast, other traits were less environmentally sensitive and have higher heritability than grain yield itself. However, FFD, grain width and thickness with over 0.9 heritability, followed by volume and TGW (0.86 and 0.84 , respectively), had the highest heritability. These characters were phenotypically the most-stable yield components and can used as independent descriptors in the breeding programs for grain yield improvement.

Some other grain morphology traits such as volume, perimeter and area also because of larger heritability than grain yield can used as indirect indices in grain yield improvement (Table 2). Grain quality traits with exception of HI after grain yield had the most affectability by environmental factors. By contrast, HI less environmentally sensitive and have higher heritability than other quality traits. Tsilo et al. (2010) also were reported larger heritabilities for kernel morphology and quality traits than grain yield. Huang et al. (2006), for TGW and quality traits and Blanco et al. (2012), for TGW and quality traits similarly were reported larger heritabilities than grain yield. Russo et al. (2014), also observed high heritability for TGW, but they had lower heritabilities for grain size and shape. However, heritability estimates for each trait can be different, depending upon the genetic material, environment and the method of computation (Blanco et al., 2012).

As a result of genetic correlations, several kernel size and shape measurements are inherently correlated, like length versus $A R$, area and perimeter $(r=0.65,0.74$ and 0.97 respectively) and width versus thickness (0.46). According to strong associations among these traits, it is possible with increasing of one of them, the other traits creased. Rasheed et al. (2014) and Russo et al. (2014), also reported similar correlations for mentioned traits in bread and durum wheat. respectively.

In accordance with the results of Rasheed et al. (2014), other important derived measurements like volume and perimeter on the contrary FFD were also positively correlated with length and width. So, with the contemporary increasing of grain length and width, volume and perimeter can creased. 


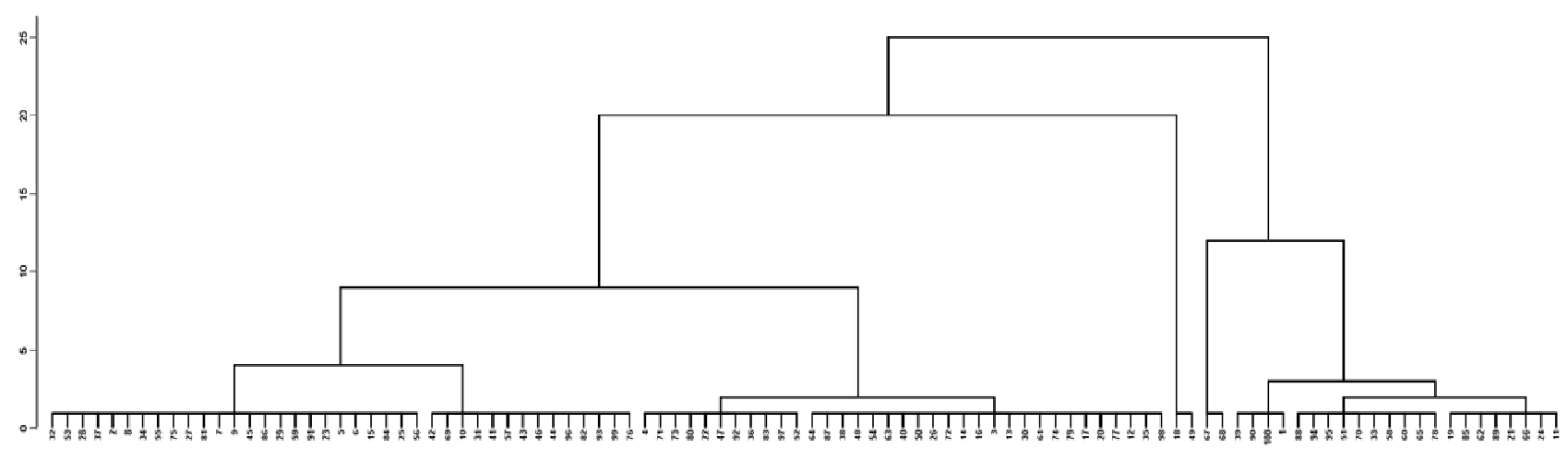

Fig. 1. Dendrogram produced using Ward's minimum variance method based on similarity matrix of bread wheat landraces

Roundness showed significant positive correlation only with thickness. However, this trait had poor positive correlation with other grain morphology traits. So, It seems with the selection of kernel with more thickness, the roundness will be creased. This positive significant association between roundness and thickness before reported by Rasheed et al. (2014). However, Russo et al. (2014), reported a significant positive association between roundness and length, and a significant negative correlation between roundness and width.

The weak correlation of AR and roundness with TGW with estimate of $r=0.16$ and $r=0.06$, respectively, giving the first indication that these traits are independent. However, all grain morphology traits with the exception of $A R$ and roundness showed a strong and positive relationship with TGW. According to correlation result, it would be preferred if grain size and shape were used in selection to increase grain weight. Gegas et al. (2010) and Rasheed et al. (2014), also reported a such correlations between TGW and above mentioned traits. Despite the strong correlation between TGW and grain morphology traits, GPC showed negative significant association with TGW. Meanwhile, other quality traits with exception of $\mathrm{HI}$ had negatively correlation with TGW, range from -0.05 to 0.17 for ZS and WA, respectively. Therefore, by the creasing of grain quality, TGW can be decreased. It can be a result of wheat cultivars with high grain yield and low quality or vice versa. Other researchers also have similar result and reported grain quality traits such as GPC in wheat have negatively correlated with grain yield and any genetic improvement in GPC has been restricted by the negative correlation between productivity and GPC (Kamra 1971; Bhatia 1975; Loffler and Busch, 1982 and Blanco et al., 2012).

In this study, all morphology traits with exception of AR and roundness showed strong and positive correlation with grain yield, meanwhile, GPC and WA had significant negative correlation with grain yield. The efficiency of indirect selection depends on the correlation between a selected trait and a target trait as well as the heritability of the selected trait (Blanco et al., 2012). As a result of our study, all morphology traits with exception of AR and roundness with moderate to high heritability, and high positive correlation with TGW had good efficiency as indirect selection for TGW. Gegas et al. (2010), also confirmed that kernel size and shape were largely independent traits in a study of six wheat populations.
Based on stepwise multiple regression analysis as a multiple statistical method that can screen or select the most important variables through a dependent variable such as the grain weight (Draper and Smith, 1966), the two first variable that entered in model i.e. volume and FFD are the most important variables contributing to the grain weight. Three other variables including the perimeter, width and HI that entered in model in next steps are important in addition to the two mentioned variables.

At the end of stepwise regression analysis, a five variables regression model with explain more than $99.33 \%$ of TGW variation, was recognize as the best model. The other variables were not included in the analysis due to their low relative contributions. Existence of positive and significant R square (regression coefficient) of volume, FFD, width and perimeter in a successful regression equation indicates the effectiveness of these traits to increase grain weight. Considering the positive and significant regression coefficient, it could be stated that increase in the amount of these characters would increase the grain weight. Furthermore, regarding the negative and significant regression coefficient of $\mathrm{HI}$, it could be said that by increasing the amount of this trait, TGW will be reduced.

The association of grain size and shape, and quality descriptors with TGW was further resolved by path coefficient analysis which depicted the phenotypic model with more precision (Table 6). This revealed that FFD has maximum direct effect on grain weight followed by volume, whereas perimeter and width had relatively less direct effect on grain weight. On the other hand, HI had negative direct effect on grain weight and this should undergo negative selection in order to get superior genotypes with high grain weight. Although, the efficiency of indirect selection depends on the correlation between a selected trait and a target trait as well as the heritability of the selected trait, it seems the magnitude and positive or negative direct effects are also important. Therefore, FFD because of having the maximum direct effect, high correlation with TGW and high heritability as the best indirect indices for TGW was recognized in this study. The grain volume followed by perimeter and width also can be can used as a good indirect descriptors for TGW.

According to cluster analysis 100 genotypes of wheat separated into 5 clusters, a range of two to 39 members (Fig. 1). The cluster III and IV had the highest and lowest average for the most traits, and identified as the most valuable and the least significant clusters, respectively. 
Though cluster analysis grouped genotypes together with greater morphological similarity, the clusters did not necessarily include all genotypes from same origin.

\section{Conclusion}

Conclusively, we found high diversity for all traits in this collection of Iranian bread wheat landraces, specialty for grain size and shape. The most of descriptors had higher heritability than TGW. FFD and volume had high correlation with TGW and explained the most of TGW variation. These former traits as indirect selection indices can be use for improving grain weight and enhanced our deep understanding on grain weight components in wheat.

\section{Acknowledgments}

We kindly thank Seed and Plant Improvement Research Institute, Karaj, Iran, for providing various valuable lines for the development of this research.

\section{References}

Abdipour M, Ramezani HR, Bavei V, Talaee S (2013). Effectiveness of Canopy Temperature and Chlorophyll Content Measurements at Different Plant Growth Stages for Screening of Drought Tolerant Wheat Genotypes. American-Eurasian Journal of Agricultural \& Environmental Sciences 13:1325-1338.

Baril CP (1992). Factor regression for interpreting genotype-environment interaction in bread-wheat trials. Theoretical and Applied Genetics 83:1022-1026.

Bezant J, Laurie D, Pratchett N, Chojecki J, Kearsey M (1997). Mapping QTL controlling yield and yield components in a spring barley (Hordeum vulgare $\mathrm{L}$ ) cross using marker regression. Molecular Breeding 29:29-38.

Bhatia CR (1975). Criteria for early generation selection in wheat breeding programmes or improving protein productivity. Euphytica 24:789-794.

Blanco A, Mangini G, Giancaspro A, Giove S, Colasuonno P, Simeone R, Signorile A, De Vita P, Mastrangelo AM, Cattivelli L, Gadaleta A (2012). Relationships between grain protein content and grain yield components through quantitative trait locus analyses in a recombinant inbred line population derived from two elite durum wheat cultivars. Molecular Breeding 30:79-92.

Breseghello F, Sorrells ME (2007). QTL analysis of kernel size and shape in two hexaploid wheat mapping populations. Field Crops Research 101:172-179.

Breseghello F, Sorrells ME (2006). Association mapping of kernel size and milling quality in wheat cultivars (Triticum aestivum L.). Genetics 172:1165-1177.

Calderini DF, Reynolds MP (2000). Changes in grain weight as a consequence of de-graining treatments at pre- and post-anthesis in synthetic hexaploid wheats. Australian Journal of Plant Physiology 27:183-191.

Chasten TG, Ward KJ, Wysocki DJ (1995). Stand establishment responses of soft white winter wheat to seedbed residue and seed size. Crop Science 35:213-218.
Clarke JM, McCaig TN, DePauw RM, Knox RE, Clarke FR, FernandezMR, Ames NP (2005). Strongfield durum wheat. Canadian Journal of PlantScience 85:651-654.

Cui F, Ding AM, Lij, Zhao CH, LiXF, FengDS, Wang XQ, WangL, Gao J, Wang HG (2011). Wheat kernel dimensions: how do they contribute to kernel weight at an individual QT1? Joumal of Genetics 90:409-425.

De Ambrogio E, Ranieri R (2002). Durum wheat breeding aiming at yield stability and high pasta-making quality. In: Mare C, Faccioli P, Stanca AM (Eds). Proceedings of EUCARPIA cereal section meeting, 21-25 Nov 2002, Salsomaggiore, Italy. I.S.C. Fiorenzuolapp 332-335.

DeSouza N (2010).High-throughput phenotyping. Nat Methods 7(1):36.

Deng S, Wu X, Wu Y, Zhou R, Wang H, Jia J, Liu S (2011). Characterization and precise mapping of a QTL increasing spike number with pleiotropic effects in wheat. Theoretical and Applied Genetics 122:281-289.

Draper NR, Smith H (1966). Applied Regression Analysis, Wiley, New York,NY,USA pp 335-338.

Evers AD, Cox RI, Shaheedullah MZ, Withey RP (1990). Predicting milling extraction rate by image analysis of wheat grains. Annals of Applied Biology 25:417-426.

Fuller DQ (2007). Contrasting patterns in crop domestication and domestication rates: Recent archaeobotanical insights from the Old World. Annals of Botany 100:903-924.

Gegas VC, Nazari A, Griffiths S, Simmonds J, Fish L, Orford S, Sayers L, Doonan JH, Snape JW (2010). A genetic frame work for grain size and shapevariation in wheat. Plant Cell 22:1046-1056.

Giura A, Saulescu NN (1996). Chromosomal location of genes controlling grain size in a large-grained selection of wheat (Triticum aestivum $\mathrm{L}$ ). Euphytica 89:77-80.

Houle D, Govindaraju DR, Omholt S (2010). Phenomics: the next challenge. Nature Reviews Genetics 11:855-866.

Huang XQ, Cloutier S, Lycar L, Radovanovic N, Humphreys DG, Noll JS, Somers DJ, Brown PD (2006). Molecular detection of QTL for agronomic and quality traits in a doubled haploid population derived from two Canadian wheats (Triticum aestivum L). Theoretical and Applied Genetics 113:753-766.

Jia H, Wan H, Yang S, Zhang Z, Kong Z, Xue S, Zhang L, Ma Z (2013). Genetic dissection of yield-related traits in a recombinant inbred line population created using a key breeding parent in China's wheat breeding. Theoretical and Applied Genetics 126:2123-2139.

Johnson VA, Dreier AF, Grabouski PH (1973). Yield and protein responses to nitrogen fertilizer of two winter wheat varieties differing in inherent protein content of their grain. Agronomyjournal 65:259-263.

Kalous JR, Martin JM, Sherman JD, Heo HY, Blake NK, Lanning SP, EckhoffJLA, Chao S, AkhunovE, Talbert LE (2015). Impact of the D genome and quantitative trait loci on quantitative traits in a spring durum by spring bread wheat cross. Theoretical and Applied Genetics 128:1799-1811.

Kamra OP (1971). Genetic modification of seed protein quality in cereals and legumes.ZPflanzenzucht 65:293-306.

Koebner RMD, Snape JW (1999). Wheat ecology, physiology of yield determination. In: Satorre EH, Slafer GA (Eds). Food Products Press, 
236 New Yorkpp 441-460.

Licker R, Johnston M, Barford C, Foley JA, Kucharik CJ, Monfreda C, Ramankutty N (2010). Mind the Gap: How do climate and agricultural management explain the yield gap of croplands around the world? Global Ecology and Biogeography 19:769-782.

Loffler CM, Busch RH (1982). Selection for grain protein, grain yield, and nitrogen partitioning efficiency in hard red spring wheat. Crop Science 22:591-595.

Maccaferri M, Sanguineti MC, Demontis A, El-Ahmed A, del Moral LG, MaaloufF, Nachit M,Nserallah N, Ouabbou H, RhoumaS, VillegasD, Tuberosa $\mathrm{R}$ (2011). Association mapping in durum wheat grown across a broad range of water regimes. Journal of Experimental Botany 62:409438.

Montes JM, Melchinger AE, Reif JC (2007). Novel throughput phenotyping platforms in plant genetic studies. Trends in Plant Sciences 12:433-436

Moragues M, Moralejo MA, Sorrells ME, Royo C (2007). Dispersal of durum wheat landraces across the Mediterranean basin assessed by AFLPs and microsatellites. Genetic Resources and Crop Evolution 54:1133-1144.

Moragues M, Zarco-Hernandez J, Moralejo MA, Royo C (2006). Genetic diversity of glutenin protein subunits composition in durum wheat landraces [Triticum turgidum sspturgidum convar. durum (Desf.) MacKey] from the Mediterranean basin. Genetic Resources and Crop Evolution 53:993-1002.

Okamoto Y, Nguyen AT, Yoshioka M, Iehisa JCM, Takumi S (2013). Identification of quantitative trait loci controlling grain size and shape in the $\mathrm{D}$ genome of synthetic hexaploid wheat lines. Breeding Science 63:423-429.

OuryFX, Berard P, Brancourt-Hulmel M,Depatureaux C, Doussignault G, Galic N, Giraud A, Heumez E, Lecompte C, Pluchard P, Rolland B, Rousset M, TrottetM (2003). Yield and grain protein concentration in bread wheat: a review and a study of multi-annual data from a French breeding program. Journal of Plant Breeding and Genetics 57:59-68.

Palm CA, Smukler SM, Sullivan CC, Mutuo PK, Nyadzi GI, Walsh MG (2010). Identifying potential synergies and trade-offs for meeting food security and climate change objectives in sub-Saharan Africa. Proceedings of the National Academy of Sciences of the United States of America 107:19661-19666.

Patil RM, TamhankarSA, Oak MD, Raut AL, Honrao BK, Rao VS, Misra SC (2013). Mapping of QTL for agronomic traits and kernel characters in durum wheat (Triticum durum Desf.). Euphytica 190:117-129.

Peleg Z, Saranga Y, Suprunova T, Ronin YW, Roder MS, Kilian A, Korol $A B$, Fahima $T$ (2008). High-density genetic map of durum wheat 9 wild emmer wheat based on SSR and DArT markers. Theoretical and Applied Genetics 117:103-115.

Rasheed A, Xia X, Ogbonnaya F, Mahmood T, Zhang Z, Mujeeb- Kazi A, He Z (2014). Genome-wide association for grain morphology in synthetic hexaploid wheats using digital imaging analysis. BMC Plant Biology 14:128.
Russo MA, Ficco DBM, Laido G, Marone D, Papa R, Blanco A, Gadaleta A, De Vita P, Mastrangelo AM (2014). A dense durum wheat $\times T$. dicoccum linkage map based on snp markers for the study of seed morphology. Molecular Breeding 34:1579-1597.

Sears RG (1998). Improving grain protein concentration and grain yield in USA hard winter wheat. In: Fowler DB, Geddes WE, Johnston AM, Preston KR (Eds). Wheat protein production and marketing. Printcrafters Inc., Winnipeg.

Shi JQ, Li RY, Qiu D, Jiang CC, Long Y, Morgan C, Bancroft Ian, Zhao J, Meng J (2009). Unraveling the complex trait of crop yield with quantitative trait loci mapping in Brassica napus. Genetics 182:851-861.

Stuber CW, Johnson VA, Schmidt JW (1962). Grain protein content and its relationship to other plant and seed characters in the parents and progeny of a cross Triticum aestivum L. CropScience 2:506-508.

Sun XY, Wu K, Zhao Y, Kong FM, Han GZ, Jiang HM, Huang XJ, Li RJ, Wang HG, Li SS (2009). QTL analysis of kernel shape and weight using recombinant inbred lines in wheat. Euphytica 165:615-624

Tsilo TJ, Hareland GA, Simsek S, Chao S, Anderson JA (2010.). Genome mapping of kernel characteristics in hard red spring wheat breeding lines. Theoretical and Applied Genetics 121:717-730.

Wang L, Ge H, Hao C, Dong Y, Zhang X (2012). Identifying loci influencing 1,000-kernel weight in wheat by microsatellite screening for evidence of selection during breeding. PLOSONE7(2): e29432.

Ward JH (1963). Hierachical group to optimize an objective function. Journal of the American Statistical Association 58:236-244.

Williams K, Munkvold J, Sorrells M (2013). Comparison of digital image analysis using elliptic Fourier descriptors and major dimensions to phenotype seed shape in hexaploid wheat (Triticum aestivum L.). Euphytica 190:99-116.

Williams K, Sorrells ME (2014). Three-Dimensional seed size and shape QTL in hexaploid wheat (Triticum aestivum L.) populations. Crop Science 54:98-110.

Xiao Y, He S, Yan J, Zhang Y, Zhang Y, Wu Y, Xia XC, Tian J, Ji W, He $\mathrm{ZH}$ (2011). Molecular mapping of quantitative trait loci for kernel morphology traits in a non-1BL.1RS $\times 1$ BL.1RS wheat cross. Crop\& PastureScience 62:625-638.

Zhang G, Wang Y, Guo Y, Zhao Y, Kong F, Li S (2015). Characterization and mapping of QTL s on chromosome $2 \mathrm{D}$ for grain size and yield traits using a mutant line induced by EMS in wheat. The Crop Journal 3:135144.

Zhang X, Deng Z, Wang Y, Li J, Tian J (2014). Unconditional and conditional QTL analysis of kernel weight related traits in wheat (Triticum aestivum L.) in multiple genetic backgrounds. Genetica 142:371-379. 